\title{
Suppression of matrix metalloproteinase production from nasal fibroblasts by macrolide antibiotics in vitro
}

\author{
K. Kanai*, K. Asano\#, T. Hisamitsu\#, H. Suzaki*
}

Suppression of matrix metalloproteinase production from nasal fibroblasts by macrolide antibiotics in vitro. K. Kanai, K. Asano, T. Hisamitsu, H. Suzaki. (C) ERS Journals Ltd 2004.

ABSTRACT: It is well known that low-dose and long-term administration of macrolide antibiotics favourably modify the clinical status of chronic airway inflammatory diseases. However, the therapeutic mode of action of macrolide antibiotics is not well understood. The present study aimed to examine the influence of macrolide antibiotics, roxithromycin (RXM) and josamycin (JM) on matrix metalloproteinase (MMP) production from nasal polyp fibroblasts (NPF) in vitro.

$\mathrm{NPF}$, at a concentration of $2.5 \times 10^{5}$ cells $\cdot \mathrm{mL}^{-1}$, were stimulated with tumour necrosis factor (TNF)- $\alpha$ in the presence of various concentrations of RXM or JM for $24 \mathrm{~h}$. MMP-2 and -9 levels in culture supernatants were analysed by ELISA, and MMP mRNA expression was examined by RT-PCR. The influence of RXM on nuclear factor (NF)- $\mathrm{B}$ and activator protein (AP)-1 activation was also examined.

Addition of RXM (but not JM) at 5.0 and $7.5 \mu \mathrm{g} \cdot \mathrm{mL}^{-1}$ significantly suppressed the production of MMP-2 and -9 from NPF induced by TNF- $\alpha$ stimulation. RXM also suppressed MMP mRNA expression through the inhibition of NF-кB and AP-1 activation.

The present results suggest that the suppressive activity of roxithromycin on MMP-2 and $\mathbf{- 9}$ production is, in part, responsible for the therapeutic action of macrolides on chronic airway inflammatory diseases.

Eur Respir J 2004; 23: 671-678.
*Dept of Otolaryngology, and ${ }^{*}$ Dept of Physiology, School of Medicine, Showa University, Tokyo, Japan.

Correspondence: K. Asano

Dept of Physiology

School of Medicine

Showa University

1-5-8 Hatanodai Shinagawa-ku

Tokyo 142-8555

Japan

Fax: 81337845368

E-mail: asanok@med.showa-u.ac.jp

Keywords: Fibroblast

in vitro

macrolide antibiotic

matrix metalloproteinase

suppression

Received: May 232003

Accepted after revision: December 182003
It is well accepted that sinobronchial syndrome involves the coexistence of chronic rhinosinusitis and chronic lower airway inflammation, i.e. chronic bronchitis and diffuse panbronchiolitis (DPB). Although these diseases are resistant to several types of treatment, low-dose and long-term administration of 14-membered macrolide antibiotics, such as erythromycin and roxithromycin (RXM), can improve the clinical condition of these diseases [1-3]. Recently, long-term use of azithromycin, a newly developed 16-membered macrolide antibiotic, has been reported to be able to favourably modify lung function of patients with cystic fibrosis $(\mathrm{CF})[4,5]$. These reports clearly indicate that the prognosis of these life-threatening airway diseases, especially DPB and CF, may improve dramatically, but the mode of action of this macrolide therapy is not well understood.

Since low-dose, long-term erythromycin treatment, which is below the minimum concentration $\left(200-600 \mathrm{mg} \cdot \mathrm{day}^{-1}\right)$ required for killing common superinfecting organisms, has been reported to be effective against DPB and chronic sinusitis [1-3], the therapeutic mode of action of macrolides is generally not believed to be due to their anti-bacterial effects. In vitro studies clearly show that erythromycin strongly suppresses chemotaxis and the production of oxygen free radicals $\left(\mathrm{O}_{2}\right.$ and $\mathrm{H}_{2} \mathrm{O}_{2}$, etc. $)$ by polymorphonuclear leukocytes when the cells were cultured in the presence of erythromycin [6, 7]. Previous work by the current authors has also shown the suppressive activity of RXM on the production of proinflammatory cytokines, such as interleukin (IL)-1 and tumour necrosis factor (TNF)- $\alpha$, from both human peripheral blood monocytes and mast cells in vitro $[8,9]$. The suppressive activity of RXM on inflammatory cytokine production has also been observed in vivo: treatment of mice with RXM once a day for $>3$ weeks markedly suppressed the appearance of IL-1, $-3,-4$ and TNF- $\alpha$ induced by intra-tracheal instillation of lipopolysaccharide and specific antigen in aqueous lung extracts [8, 10]. More recently, the authors of the present study have reported that RXM suppresses the ability of human peripheral blood T-cells to produce IL-4 and -5 (but not interferon- $\gamma$ and IL-2) after costimulatory molecule stimulation [11]. These reports strongly suggest that macrolide antibiotics may exert anti-inflammatory effects and result in favourable modification of the clinical status of chronic inflammatory diseases.

It has been previously reported that an accumulation of both neutrophils and macrophages in the airways is an important feature of chronic inflammatory diseases, the levels of which are normalised after a period of successful macrolide therapy, along with the favourable modification of clinical status in these diseases $[2,3]$. The recruitment of circulating polymorphonuclear leukocytes (e.g. neutrophils and macrophages) into inflammatory sites involves traversing both the capillary walls and the interstitium $[12,13]$. To traverse these barriers, inflammatory cells adhere to endothelial cells and degrade extracellular matrix (ECM) proteins [12, 13]. The degradation of ECM proteins, including basement membrane proteins, is regulated by matrix metalloproteinases (MMP) and their inhibitors (tissue inhibitors of metalloproteinases (TIMP)), which are secreted by a wide variety of cells, including 
inflammatory cells, epithelial cells and fibroblasts, in response to inflammatory stimuli $[13,14]$. However, currently, the influence of macrolide antibiotics on MMP and TIMP production is not fully understood [15]. Therefore, the present study was undertaken to answer the unresolved questions regarding the favourable effects of macrolide antibiotics on chronic airway inflammatory diseases by examining the influence of RXM on MMP and TIMP production from fibroblasts in response to inflammatory stimuli in vitro.

\section{Materials and methods}

\section{Macrolides}

RXM was kindly donated (Aventis Pharmaceuticals Co., Ltd, Tokyo, Japan) as a preservative-free pure powder. RXM was dissolved in $100 \%$ ethyl alcohol at $20 \mathrm{mg} \cdot \mathrm{mL}^{-1}$, diluted with RPMI-1640 medium (Sigma Chemical Co., Ltd, St Louis, MO, USA), supplemented with $10 \%$ foetal calf serum (RPMI-FCS; Irvine Scientific Co., Ltd, Santa Ana, CA, USA) at $1 \mathrm{mg} \cdot \mathrm{mL}^{-1}$ and stored at $4{ }^{\circ} \mathrm{C}$ until use. All dilutions were prepared from this stock solution by diluting with RPMI-FCS just before use. Josamycin (JM) (Sigma Chemical Co., Ltd) was dissolved in RPMI-FCS in a similar manner.

\section{Establishment of nasal polyp fibroblasts in vitro}

Nasal polyp fibroblasts (NPF) were established according to a previously described method [16]. In brief, nasal polyp specimens were surgically obtained from seven male patients (mean \pm SD: $37 \pm 17 \mathrm{yrs)}$ with chronic sinusitis, with written informed consent according to the protocol approved by the Ethics Committee of Showa University (Tokyo, Japan). Specimens $\left(\sim 1 \mathrm{~mm}^{2}\right)$ were washed several times with PBS, supplemented with $200 \mathrm{U} \cdot \mathrm{mL}^{-1}$ penicillin, $200 \mu \mathrm{g} \cdot \mathrm{mL}^{-1}$ streptomycin and $5 \mu \mathrm{g} \cdot \mathrm{mL}^{-1}$ amphotericin B. Samples were then plated at a density of 10 pieces in $100-\mathrm{mm}$ tissue culture dishes that contained antibiotic-free RPMI-FCS. When a monolayer of fibroblast-like cells was found to be confluent, cells were trypsinised and re-plated into culture dishes at a concentration of $5 \times 10^{5}$ cells $\cdot \mathrm{mL}^{-1}$ in a final volume of $10 \mathrm{~mL}$. After confluency, the cells were diluted twice and passaged. The cells were characterised [16] and used as NPF.

\section{Cell culture}

Cells (passaged six to nine times) were washed several times with RPMI-FCS and introduced into each well of 24-well culture plates in triplicate, at a concentration of $2.5 \times 10^{5}$ cells $\cdot \mathrm{mL}^{-1}$ in a volume of $1 \mathrm{~mL}$ and allowed to adhere for $24 \mathrm{~h}$. The wells were washed twice with RPMI-FCS to remove dead and unattached cells. Fresh medium, which contained $\mathrm{TNF}-\alpha$ and various concentrations of macrolide antibiotics, was then added into each well in a total volume of $2 \mathrm{~mL}$. The plates were maintained at $37^{\circ} \mathrm{C}$ in a humidified atmosphere with $5 \% \mathrm{CO}_{2}$. The culture supernatants were removed after $24 \mathrm{~h}$ and stored at $-40^{\circ} \mathrm{C}$ until use. Cells were cultured in a similar manner for examining nuclear factor (NF)- $\kappa \mathrm{B}$ and activator protein (AP)-1 activities and mRNA expression, and were collected 4 and $12 \mathrm{~h}$ after culture, respectively. The cells were then stored at $-80^{\circ} \mathrm{C}$ until use [17].

\section{Assay for MMP and TIMP}

MMP-2, -9 and TIMP-2 levels in culture supernatants were examined in duplicate using commercially available ELISA test kits (Amersham Biosciences Corp., Piscataway, NJ, USA), according to the manufacturer's instructions. The sensitivity of each ELISA kit for MMP-2, -9 and TIMP-2 was $0.6 \mathrm{ng} \cdot \mathrm{mL}^{-1}, 0.6 \mathrm{ng} \cdot \mathrm{mL}^{-1}$ and $3.0 \mathrm{ng} \cdot \mathrm{mL}^{-1}$, respectively.

\section{Assay for $m R N A$ expression}

Expression of mRNA was examined using RT-PCR. Poly $\mathrm{A}^{+}$mRNA was extracted from NPF with $\mu$ MACS mRNA isolation kits (Milteny Biotec, GmbH, Bergisch Gladbach, Germany), according to the manufacturer's instructions. The first-strand cDNA synthesis from $1 \mu \mathrm{g}$ mRNA was performed with a Superscript cDNA synthesis kit (Invitrogen Corp., Carlsbad, CA, USA). Amplification of cDNA $(1 \mu \mathrm{L})$ was performed with a Takara PCR Amplification kit (Takara Shuzo, Co., Ltd, Shiga, Japan) using specific primers for MMP-2, -9, TIMP-2 and $\beta$-actin in a final volume of $30 \mu \mathrm{L}$. The primers used for RT-PCR were 5'-AGATCTTCTTCTTCAAGGACCGGTT-3' (sense) and 5'-GGCTGGTCAGTGGCTTGGGGTA-3' (anti-sense) for MMP-2, 5'-CCCACATTTGACGTCCAGAGAAGAA-3' (sense) and 5'-GTTTTTGATGCTATTGGCTGAGATCCA-3' (anti-sense) for MMP-9, 5'-CTCGCTGGACGTTGGAGGAAAGAA-3' (sense) and 5'-AGCCCATCTGGTACCTGTGGTTCA-3' (anti-sense) for TIMP-2, and 5'-CGGAACCGCTCATTGCC-3' and 5'-ACCCACACTGTGCCCATCTA-3' for $\beta$ actin [18]. The PCR conditions were as follows: $4 \mathrm{~min}$ at $94^{\circ} \mathrm{C}$, followed by 30 cycles of $30 \mathrm{~s}$ at $94^{\circ} \mathrm{C}, 30 \mathrm{~s}$ at $58^{\circ} \mathrm{C}$, and $30 \mathrm{~s}$ at $72^{\circ} \mathrm{C}$. After PCR cycling, there was a DNA extension period of $4 \mathrm{~min}$ at $72^{\circ} \mathrm{C}$ [18]. Each PCR product $(10 \mu \mathrm{L})$ was run on $3 \%$ agarose gels, visualised by a UV illuminator after SYBR Green staining (BioWhittaker Molecular Applications, Rockland, ME, USA) and photographed. The intensity of mRNA levels was corrected using $\beta$-actin transcripts, calculated by a densitometer.

\section{Assay for $N F-\kappa B$ and $A P-1$ activities}

$\mathrm{NF}-\kappa \mathrm{B}$ activity was analysed using a commercially available ELISA test kit (Active Motif, Co., Ltd, Carlsbad, CA, USA), which contains sufficient reagents and monoclonal antibodies against p50 and p65 subunits, according to the manufacturer's recommended procedure. Briefly, nuclear extract $(5 \mu \mathrm{g}$ protein) from NPF was introduced into each well of 96-well microtitre plates precoated with oligonucleotide containing the NF- $\mathrm{KB}$ consensus site (5'-GGGACTTTCC-3') in a volume of $20 \mu \mathrm{L}$, and incubated for $1 \mathrm{~h}$ at $25^{\circ} \mathrm{C}$. After washing three times, $100 \mu \mathrm{L}$ of monoclonal antibody against p50 or p65 was added to the appropriate wells, and incubated for a further $1 \mathrm{~h}$ at $25^{\circ} \mathrm{C}$. Anti-IgG HRP-conjugate in a volume of $100 \mu \mathrm{L}$ was then added and incubated for $1 \mathrm{~h}$ at $25^{\circ} \mathrm{C}$. Absorbance at $450 \mathrm{~nm}$ was measured after the addition of tetramethylbenzine solution. AP-1 activity was also examined using a commercially available ELISA test kit (Active Motif, Co., Ltd) which contains sufficient reagents and monoclonal antibodies against Fra 1 and Jun B, according to the manufacturer's instructions. Using the manufacturer's data sheets, the amount of NF- $\kappa \mathrm{B}$ and AP-1, bound to DNA can be measured by these two ELISA systems.

\section{Statistical analysis}

The difference between control and experimental data was analysed statistically using ANOVA, followed by Fisher's PLSD test. A p-value $<0.05$ was considered significant. 


\section{Results}

\section{Production of MMP from NPF in response to $T N F-\alpha$} stimulation in vitro

The dose-response relationship of TNF- $\alpha$ stimulation on the ability of NPF to produce MMP in vitro was examined. NPF from seven donors were stimulated with various concentrations of TNF- $\alpha$ for $24 \mathrm{~h}$ and MMP levels in culture supernatants were examined by ELISA. As shown in figure 1a, addition of TNF- $\alpha$ at $>10 \mathrm{ng} \cdot \mathrm{mL}^{-1}$ into cell cultures enhanced the ability of NPF to produce MMP-2: culture supernatants from cells stimulated with TNF- $\alpha$ contained much higher levels of MMP-2 as compared with nonstimulated controls. In the case of MMP-9 production, addition of $\mathrm{TNF}-\alpha<10 \mathrm{ng} \cdot \mathrm{mL}^{-1}$ into cell cultures did not significantly affect MMP-9 production from NPF, however, TNF- $\alpha$ at $20 \mathrm{ng} \cdot \mathrm{mL}^{-1}$ caused a significant increase in MMP-9 levels in culture supernatants (fig. $1 \mathrm{~b}$ ). The data in figure $1 \mathrm{~b}$ also show that the optimum concentration of TNF- $\alpha$ needed to stimulate MMP-9 production was $20-35 \mathrm{ng} \cdot \mathrm{mL}^{-1}$.
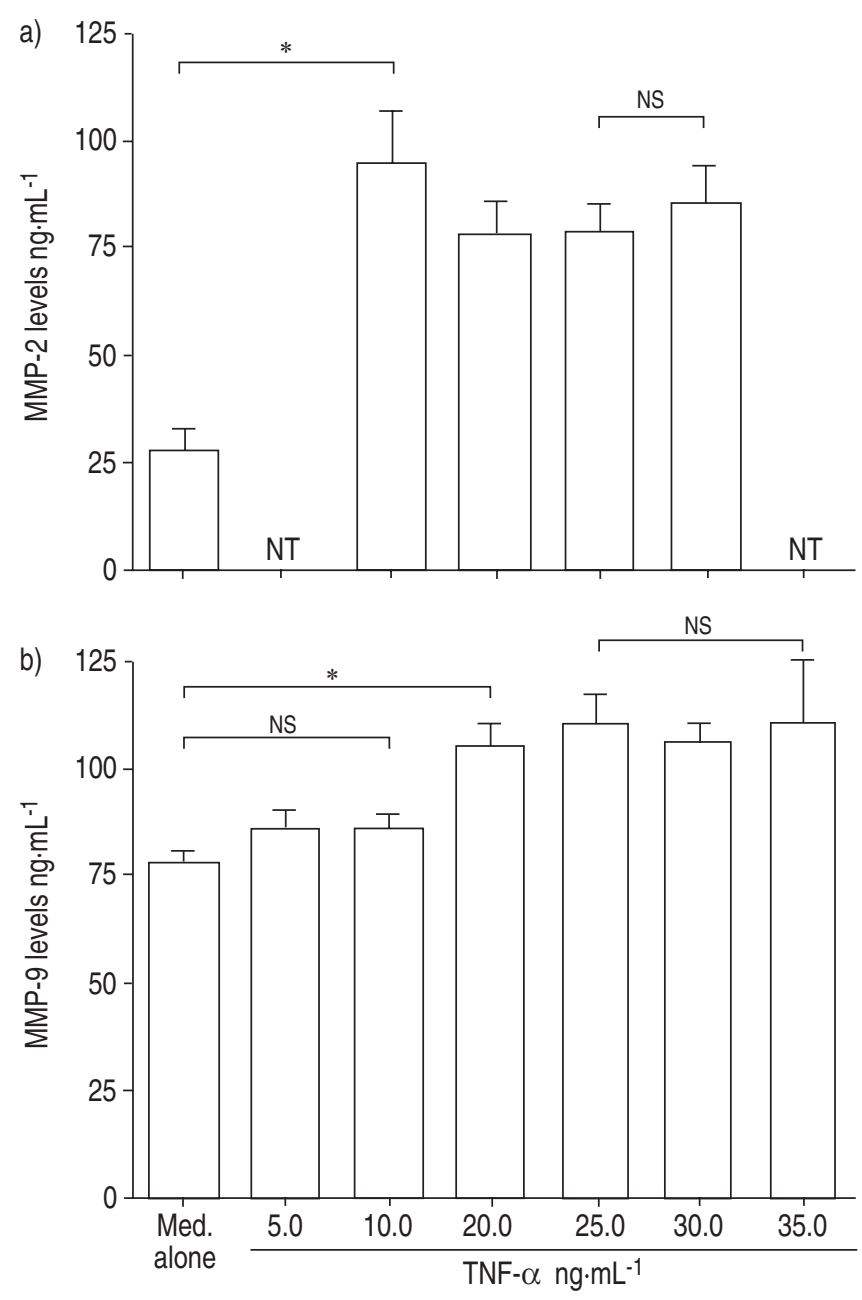

Fig. 1.- Dose response profile of tumour necrosis factor (TNF)- $\alpha$ on matrix metalloproteinase (MMP) production from nasal polyp fibroblasts (NPF) in vitro. NPF were stimulated with various concentrations of TNF- $\alpha$ for $24 \mathrm{~h}$. MMP-2 (a) and -9 (b) concentrations in culture supernatants were assayed by ELISA. Data are presented as the mean \pm SE of seven different subjects. NT: not tested. NS: nonsignificant; *: $\mathrm{p}<0.05$.
Influence of macrolide antibiotics on MMP and TIMP-2 production from NPF after TNF- $\alpha$ stimulation

The influence of RXM and JM on TNF- $\alpha$-induced MMP-2 and -9 production from NPF was examined. NPF from seven donors were stimulated with $25 \mathrm{ng} \cdot \mathrm{mL}^{-1}$ of TNF- $\alpha$ in the presence of various concentrations of either RXM or JM. MMP-2 and -9 levels in culture supernatants were examined $24 \mathrm{~h}$ later. As shown in figure 2a, RXM suppressed MMP-2 production from NPF, which is enhanced by TNF- $\alpha$ stimulation. The minimum suppressive concentration of RXM was $7.5 \mu \mathrm{g} \cdot \mathrm{mL}^{-1}$. JM could not suppress MMP-2 production even when $10 \mu \mathrm{g} \cdot \mathrm{mL}^{-1}$ of the agent was added to cell cultures (fig. 2b). Addition of RXM into cell cultures at $>5.0 \mu \mathrm{g} \cdot \mathrm{mL}^{-1}$ completely suppressed MMP-9 production from TNF- $\alpha-$ stimulated NPF: MMP-9 levels in cell culture supernatants with $>5.0 \mu \mathrm{g} \cdot \mathrm{mL}^{-1} \mathrm{RXM}$ were not significantly different to control cultures (fig. 3a). In contrast, JM did not suppress TNF- $\alpha$-induced MMP-9 production from NPF, even when $10 \mu \mathrm{g} \cdot \mathrm{mL}^{-1}$ was added to cell cultures (fig. $3 \mathrm{~b}$ ). The influence of macrolide antibiotics on TIMP production from NPF was
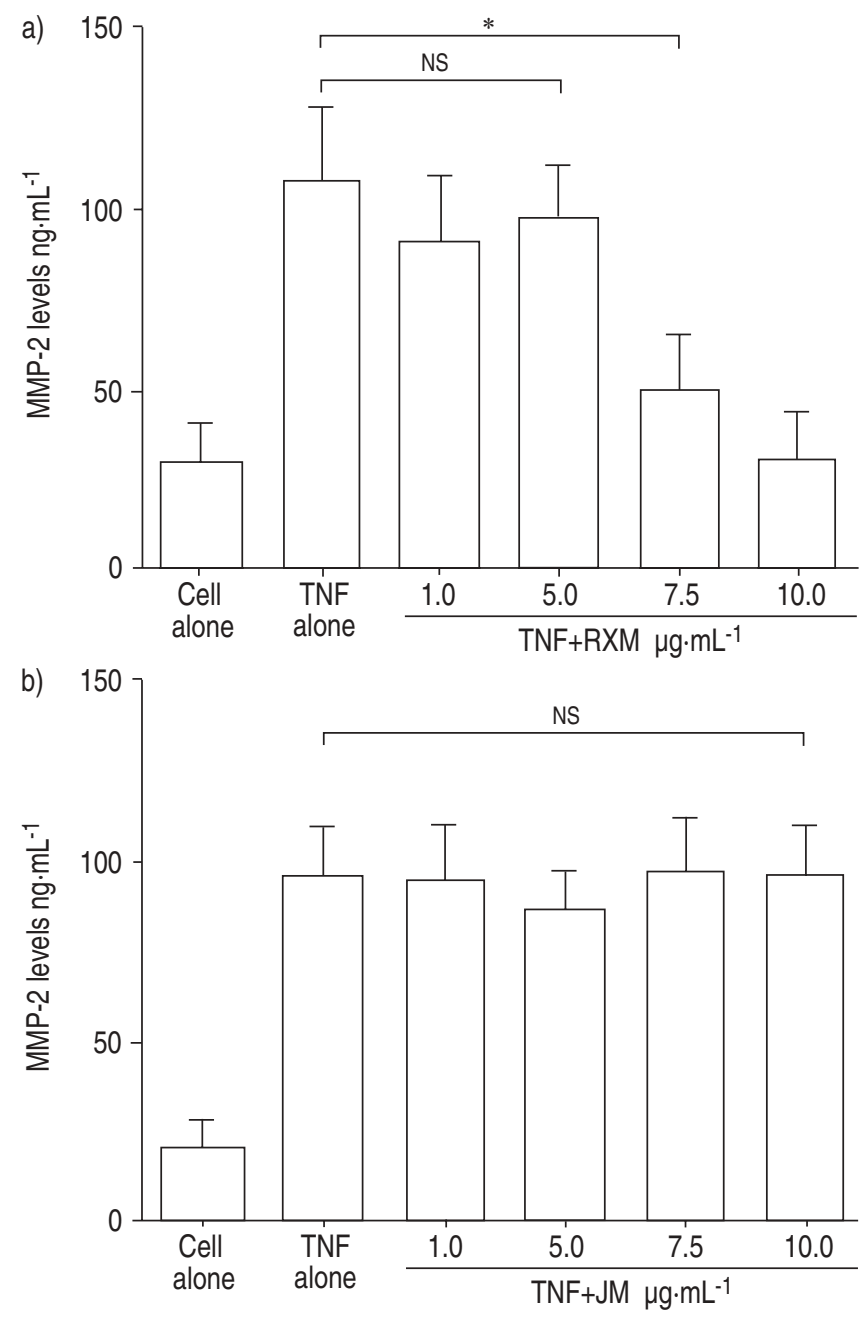

Fig. 2.-Influence of macrolide antibiotics on matrix metalloproteinase (MMP)-2 production from nasal polyp fibroblasts (NPF) in vitro. NPF were stimulated with tumour necrosis factor (TNF)- $\alpha$ in the presence of various concentrations of either roxithromycin (RXM; a) or josamycin (JM; b) for $24 \mathrm{~h}$. MMP-2 levels in the culture supernatants were assayed by ELISA. Data are presented as the mean \pm SE of seven different subjects. NS: nonsignificant; *: $\mathrm{p}<0.05$. 

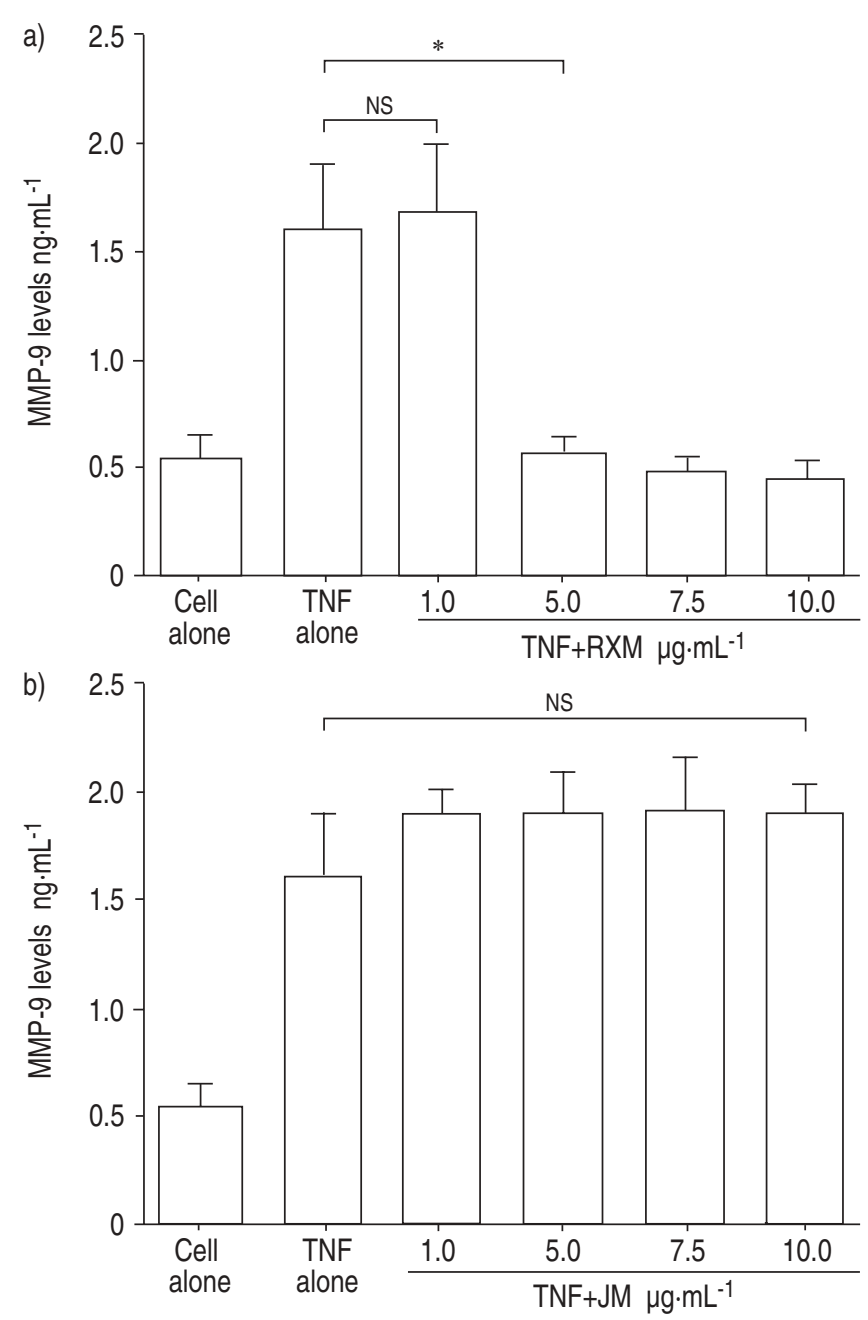

Fig. 3.-Influence of macrolide antibiotics on matrix metalloproteinase (MMP)-9 production from nasal polyp fibroblasts (NPF) in vitro. NPF were stimulated with tumour necrosis factor (TNF)- $\alpha$ in the presence of various concentrations of either roxithromycin (RXM; a) or josamycin (JM; b) for $24 \mathrm{~h}$. MMP-9 levels in the culture supernatants were assayed by ELISA. Data are presented as the mean \pm SE of seven different subjects. NS: nonsignificant; *: $\mathrm{p}<0.05$.

also examined. The data in figures $4 \mathrm{a}$ and $4 \mathrm{~b}$ show that the addition of macrolide antibiotics (RXM and JM) into cell cultures did not suppress TIMP production from NPF in response to $\mathrm{TNF}-\alpha$ stimulation.

\section{Suppressive activity of macrolide antibiotics on MMP and TIMP $m R N A$ expression}

This experiment was carried out to examine whether RXM suppressed mRNA expression and resulted in the inhibition of protein production, or whether RXM directly inhibited protein production. As shown in figure 5, RXM did not affect TNF- $\alpha$-induced TIMP-2 mRNA expression even when $7.5 \mu \mathrm{g} \cdot \mathrm{mL}^{-1}$ of the agent was added to cell cultures. However, MMP-2 mRNA expression was suppressed by RXM when the agent was added to cell cultures at $7.5 \mu \mathrm{g} \cdot \mathrm{mL}^{-1}$. This suppressive activity of RXM on mRNA expression was also observed for MMP-9 mRNA expression, in which the suppressive activity appeared at $5 \mu \mathrm{g} \cdot \mathrm{mL}^{-1}$ (fig. 5). Graphs
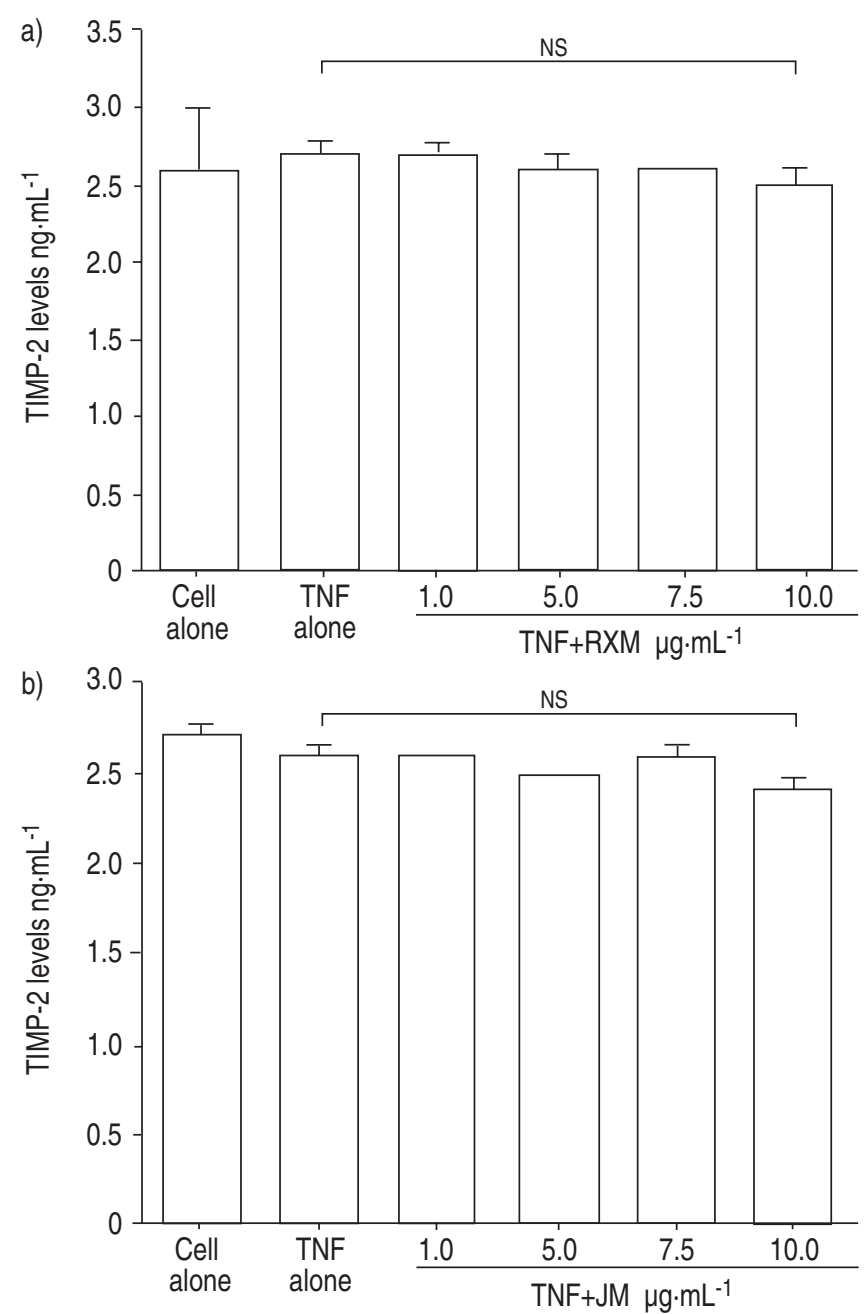

Fig. 4.-Influence of macrolide antibiotics on tissue inhibitors of matrix metalloproteinases (TIMP)-2 production from nasal polyp fibroblasts (NPF) in vitro. NPF were stimulated with tumour necrosis factor (TNF)- $\alpha$ in the presence of various concentrations of either roxithromycin (RXM; a) or josamycin (JM; b) for $24 \mathrm{~h}$. TIMP-2 levels in the culture supernatants were assayed by ELISA. Data are presented as the mean \pm SE of seven different subjects. NS: nonsignificant.

showing the ratio of the target protein to $\beta$-actin obtained from seven different subjects confirmed these effects.

\section{Suppressive activity of $R X M$ on $N F-\kappa B$ and $A P-1$ activation}

The influence of RXM on NF- $\mathrm{RB}$ and AP-1 activation in $\mathrm{NPF}$ by TNF- $\alpha$ stimulation in vitro was examined. NPF were stimulated with TNF- $\alpha$ in the presence of various concentrations of RXM for $4 \mathrm{~h}$. The nuclear extracts were prepared, and NF- $\kappa \mathrm{B}$ and AP-1 activities were examined. Addition of RXM at low concentrations $\left(1\right.$ and $\left.5 \mu \mathrm{g} \cdot \mathrm{mL}^{-1}\right)$ into cell cultures did not affect NF- $\kappa \mathrm{B}$ activation: optical density at $450 \mathrm{~nm}$ in experimental groups was similar to those in appropriate controls (fig. 6). However, higher concentrations $\left(7.5 \mu \mathrm{g} \cdot \mathrm{mL}^{-1}\right)$ of RXM caused significant inhibition of p50 and p65 activation. This inhibition was further increased when $10 \mu \mathrm{g} \cdot \mathrm{mL}^{-1} \mathrm{RXM}$ was added to cell cultures (fig. 6). RXM also exerted a dose-dependent suppressive effect on TNF- $\alpha$ stimulated AP-1 (Fra 1 and Jun B) activation (fig. 7). 


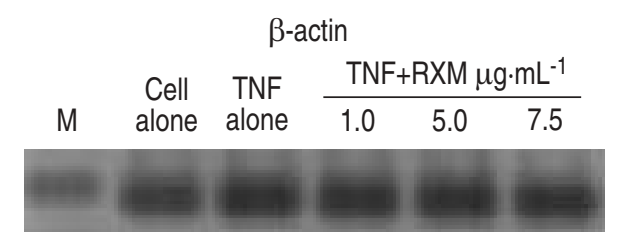

M

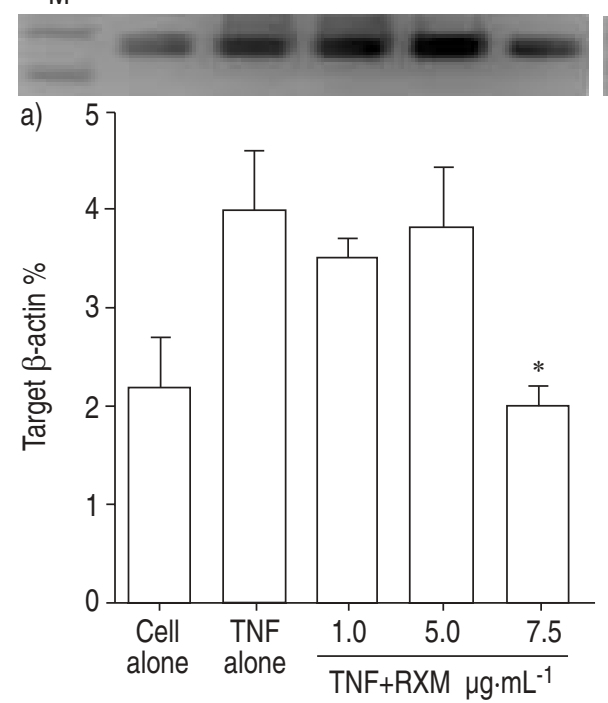

M

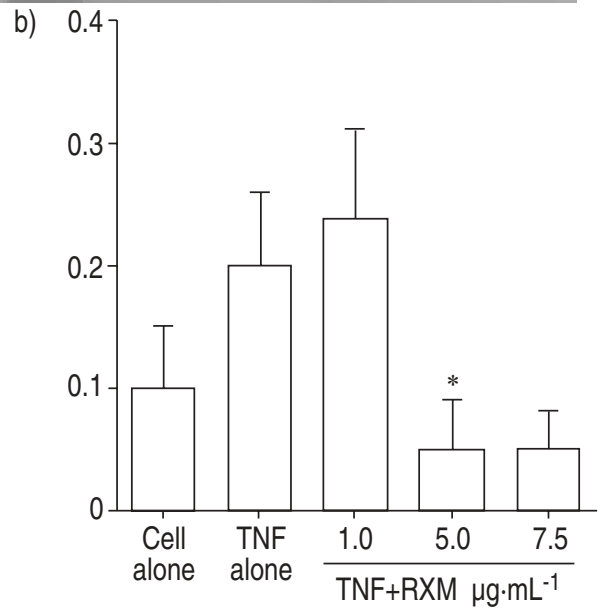

M

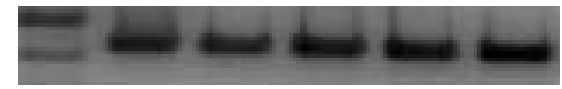

c) 2.5

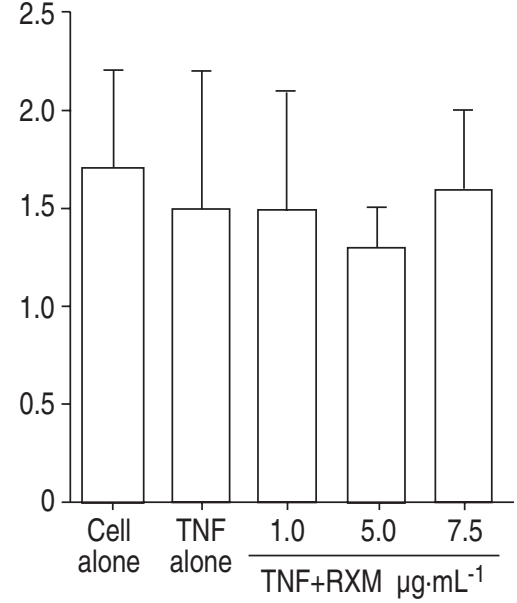

Fig. 5. - Influence of roxithromycin (RXM) on the expression of mRNA for matrix metalloproteinase (MMP)-2 (a), -9 (b), and tissue inhibitors of matrix metalloproteinases (TIMP)-2 (c) in nasal polyp fibroblasts (NPF) in vitro. NPF were stimulated with tumour necrosis factor (TNF)- $\alpha$ in the presence of various concentrations of RXM for $12 \mathrm{~h}$. One typical result out of seven subjects is shown in the photographs. Intensity of mRNA levels corrected by $\beta$-actin is presented as the mean \pm SE of seven different subjects. M: marker. *: $\mathrm{p}<0.05$ as compared with TNF alone.

The minimum concentration of RXM which caused significant suppression of AP-1 activation was $5 \mu \mathrm{g} \cdot \mathrm{mL}^{-1}$ (fig. 7).

\section{Discussion}

The present results clearly show that RXM suppresses MMP-2 and -9 production from NPF after TNF- $\alpha$ stimulation in vitro. However, this effect was not seen with JM. In addition, it has been shown that the suppressive activity of RXM is due to inhibition of NF- $\mathrm{BB}$ - and AP-1-dependent MMP mRNA expression, rather than direct inhibition of protein production.

Pharmacological studies have revealed that, after oral administration of RXM at doses of either 150 or $300 \mathrm{mg}$, plasma concentrations of this agent gradually increase and attain a plateau at $6.8 \mu \mathrm{g} \cdot \mathrm{mL}^{-1}$ or $10.0 \mu \mathrm{g} \cdot \mathrm{mL}^{-1}$, respectively $[19,20]$. These reports suggest that the findings of the present in vitro study may reflect the biological function of RXM in vivo.

Histological observations of the lungs from CF and DPB have revealed thickening of walls (including the basement membrane) of the respiratory bronchioles with predominant infiltration of polymorphonuclear leukocytes, especially neutrophils [3, 21]. These inflammatory changes were accompanied by oedema and extended to the peribronchiolar tissues $[3,21]$. It is well accepted that chronic sinusitis is a chronic inflammatory disease of the upper airways, featuring inflammatory cell infiltration, modifications of epithelial differentiation and tissue remodelling, which includes basement membrane thickening, ECM accumulation and oedema $[22,23]$. These morphological changes are linked to alterations in the activities of both MMP and their counterregulatory inhibitors, TIMP. The MMP are a group of zinc-dependent endopeptidases, which are capable of digesting the ECM and basement membrane [12-14].

Among the MMP family, MMP-2 and -9 more specifically degrade native type IV and $\mathrm{V}$ collagen and denatured collagens, as well as elastin, which are the most important components of the ECM and basement membrane in airway walls [12-14]. These MMP are produced by numerous cell types, including fibroblasts and neutrophils, in response to inflammatory stimuli, and mediate transmigration of inflammatory cells through the basement membrane to propagate inflammation [13, 24]. MMP also appear to be responsible for microvascular permeability leading to oedema and enhancement of cell transmigration [12, 24]. Recent in vitro studies clearly demonstrated that erythromycin could inhibit MMP-9 production from the human monocyte-like cell line U937 and mouse splenic macrophages, through the suppression of MMP-9 mRNA expression [15]. This suppressive activity of erythromycin on MMP-9 is also reported to correlate well with the inhibitory action of this agent on macrophage migration [15]. Therefore, it is reasonable to speculate that the inhibitory action of RXM on both MMP-2 and -9 production from NPF may be one of the therapeutic mechanisms by which macrolide antibiotics exert their effects in chronic inflammatory airway diseases. This suggestion may be supported by the finding that JM, which has been ineffective in the empirical treatment of DPB [2, 3], does not exert suppressive effects on MMP production. Most MMP are secreted from cells as inactive proenzymes, which are cleaved extracellularly to produce their active forms [25]. The extracellular activity of MMP is regulated by TIMP, which are secreted by the same cell types that produce MMP [25]. The present results clearly show that RXM cannot suppress the ability of NPF to produce TIMP-2, suggesting that MMP secreted in low amounts during macrolide treatment are 

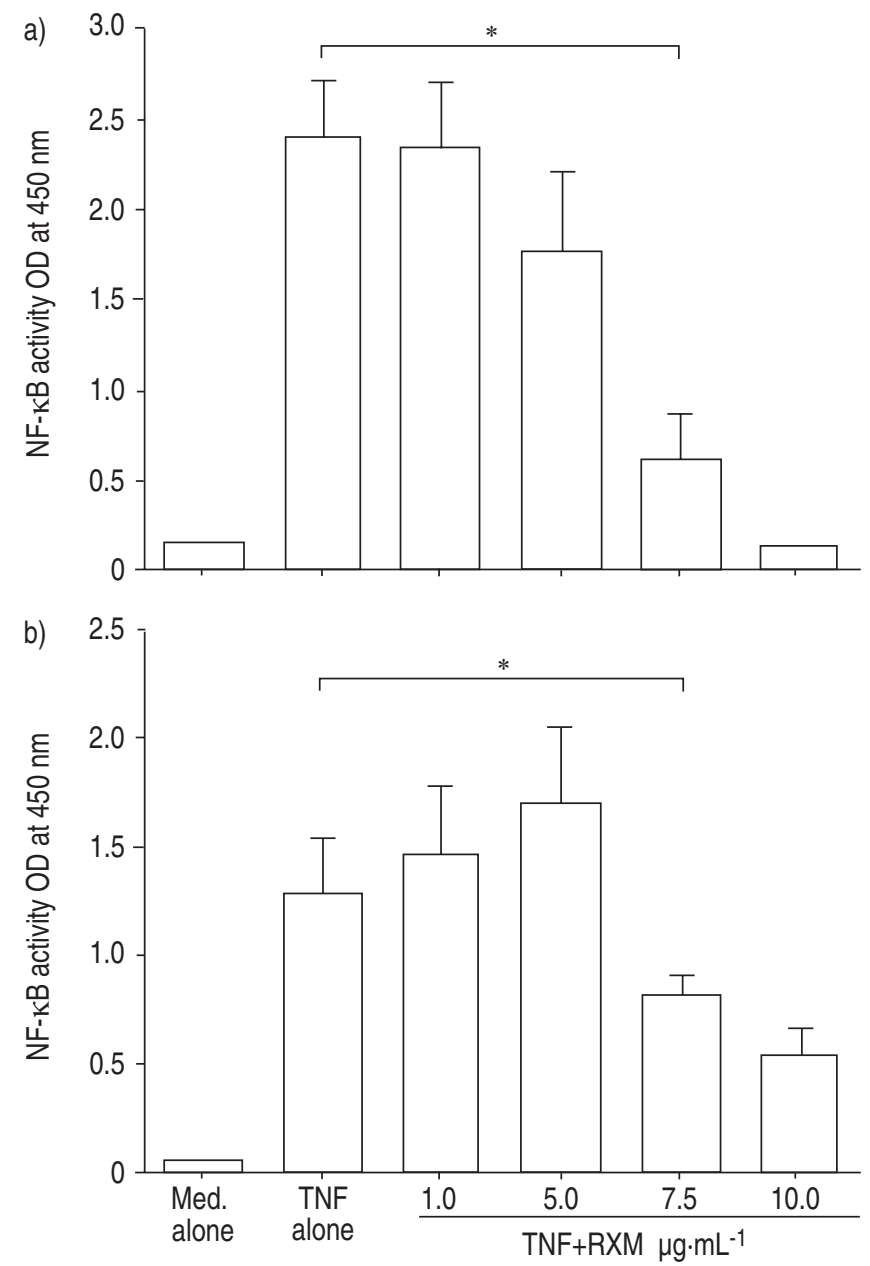

Fig. 6. - Influence of roxithromycin (RXM) on nuclear factor (NF)$\kappa \mathrm{B}$ activation in nasal polyp fibroblasts (NPF) in vitro. NPF were stimulated with tumour necrosis factor (TNF)- $\alpha$ in the presence of various concentrations of RXM for 4 h. p50 (a) and p65 (b) activities were examined by ELISA. Data are presented as the mean optical density (OD) at $450 \mathrm{~nm} \pm \mathrm{SE}$ of seven different subjects. $*$ : $\mathrm{p}<0.05$.

inactivated by TIMP, and result in the inhibition of ECM remodelling and inflammatory responses.

MMP-2 and -9 share many common features, including identical substrate specificity, but their gene expression is differentially regulated due to the distinct structure of elements and promoters in their genes [26, 27]. MMP-2 gene expression requires translocation of the transcription factor $\mathrm{NF}-\kappa \mathrm{B}$ (but not AP-1) to the nucleus and binding to promoter regions, which causes the induction of mRNA expression [28, 29]. In contrast, AP-1 protein is essential for MMP-9 gene expression [28, 30]. It has been reported that erythromycin can inhibit the activation of transcription factors, NF- $\kappa \mathrm{B}$ and AP-1 [17], suggesting that RXM inhibits the activation of $\mathrm{NF}-\kappa \mathrm{B}$ and AP-1 induced by $\mathrm{TNF}-\alpha$ stimulation and results in suppression of MMP production. This suggestion may be supported, in part, by the present results, showing the suppressive activity of RXM (at concentrations equivalent to blood concentrations in the therapeutic range) on NF- $\mathrm{BB}$ (p50 and p65) and AP-1 (Fra 1 and Jun B) activation induced by $T N F-\alpha$ stimulation. It was recently reported that expression of $\alpha 5 \beta 1$ integrin, the receptor for fibronectin, one of the important basement components, enhances MMP gene expression in fibroblasts and macrophages $[31,32]$. $\alpha 5 \beta 1$ integrin expression is also reported to be
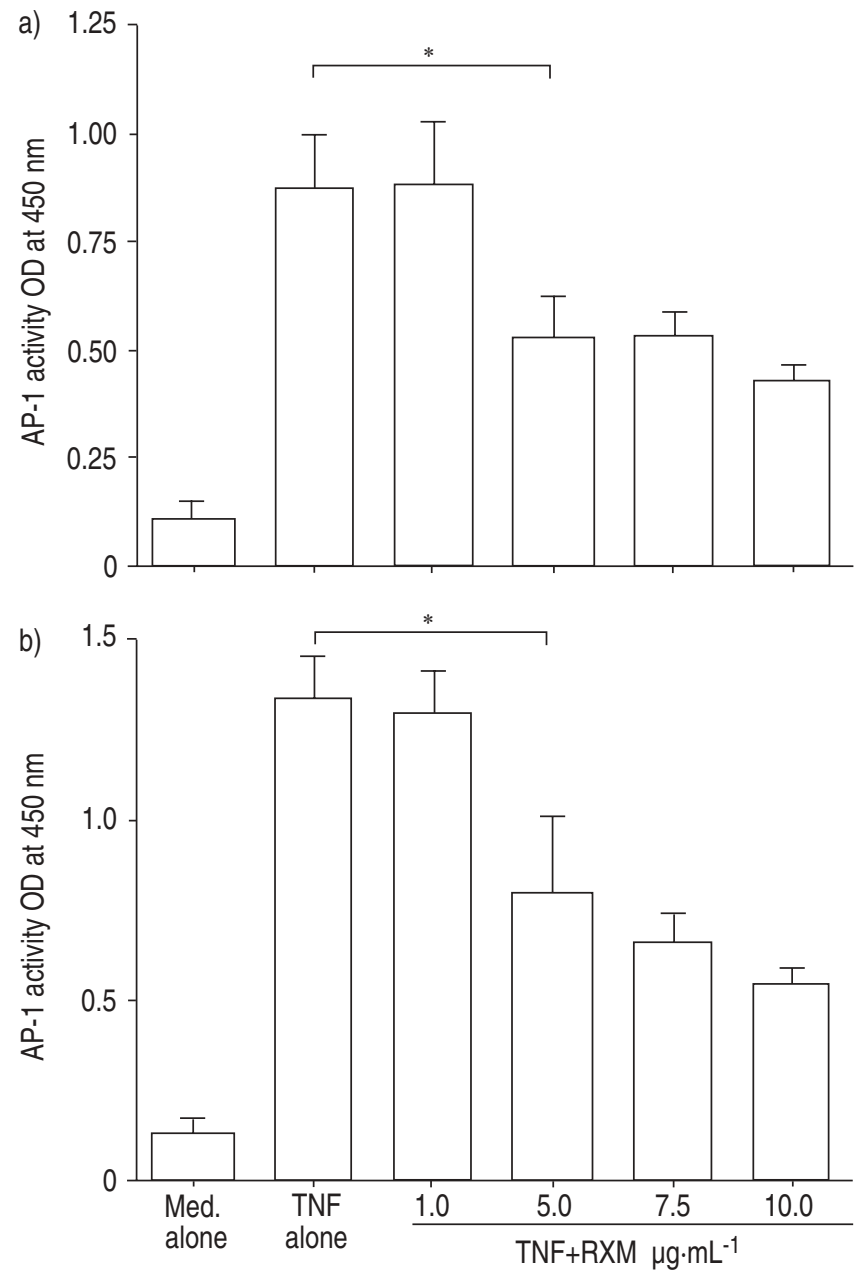

Fig. 7. - Influence of roxithromycin (RXM) on activator protein (AP)1 activation in nasal polyp fibroblasts (NPF) in vitro. NPF were stimulated with tumour necrosis factor (TNF)- $\alpha$ in the presence of various concentrations of RXM for $24 \mathrm{~h}$. Fra 1 (a) and Jun B (b) activities were examined by ELISA. Data are presented as the mean optical density (OD) at $450 \mathrm{~nm} \pm \mathrm{SE}$ of seven different subjects. *: $\mathrm{p}<0.05$.

mediated by $\mathrm{NF}-\kappa \mathrm{B}[32,33]$, suggesting the possibility that RXM might diminish the expression of $\alpha 5 \beta 1$ integrin on the fibroblast cell surface and result in the inhibition of MMP production.

TNF- $\alpha$ is a multifunctional cytokine that plays a role in inflammation, immunity and a variety of diseases. It is also accepted that TNF- $\alpha$ activates several components implicated in cellular signal transduction. Binding of TNF- $\alpha$ to the type-1 TNF receptor causes an increase in intracellular $\mathrm{Ca}^{2+}$ concentrations through calcium influx [34], and results in activation of both NF- $\kappa \mathrm{B}$ and AP-1, which are essential transcriptional factors for MMP production [28-30, 35]. Erythromycin is reported to inhibit an increase in $\mathrm{Ca}^{2+}$ concentrations in epithelial cells through the suppression of $\mathrm{Ca}^{2+}$ influx from the extracellular space [36]. Therefore, it is reasonable to speculate that RXM may suppress $\mathrm{Ca}^{2+}$ influx into NPF after TNF- $\alpha$ stimulation, resulting in the inhibition of the transcriptional factor (NF- $\kappa \mathrm{B}$ and $\mathrm{AP}-1)$ activation responsible for MMP mRNA expression.

In the cytosol, NF- $\kappa \mathrm{B}$ is found in an inactive form bound to an inhibitory molecule, I $\kappa$ B [37]. Stimulation of cells with TNF- $\alpha$ causes dissociation of NF- $\kappa$ B from I $\kappa$ B through the activation of mitogen-activated protein kinase [38]. After 
translocation into the nucleus, NF- $\mathrm{BB}$ is reduced by a cellular reducing catalyst, thioredoxin, through redox control mechanisms $[37,38]$. The reduced form of $N F-\kappa B$ then binds to the promoter region of the $\mathrm{NF}-\kappa \mathrm{B}-d e p e n d e n t$ gene $[37,38]$. Recently, it has been reported that erythromycin cannot interfere with the dissociation of $\mathrm{NF}-\kappa \mathrm{B}$ from I $\mathrm{B}$ induced by TNF- $\alpha$ stimulation in human bronchial epithelial cells [39]. Erythromycin has also been reported to be unable to suppress the translocation of NF- $\mathrm{B}$ to the nucleus, whereas erythromycin significantly suppresses the DNA-binding activity of reduced $N F-\kappa B$ and results in the inhibition of mRNA expression in an NF- $\mathrm{NB}-d e p e n d e n t$ manner [39]. From these observations, it may be interpreted from the present results that RXM prevents the binding of $N F-\kappa B$ to promoter regions in DNA and results in inhibition of MMP mRNA expression.

Recent immunohistological observations have revealed that stromal cells of squamous cell carcinoma of the lung are highly positive for MMP-1 and -9, and that fibroblasts located in the tumour-surrounding tissues are also positive for MMP-2 [40], suggesting the involvement of these MMP in highly invasive and potentially metastatic squamous cell carcinomas of the lung. Taken together, the present results may suggest that long-term use of the 14-membered macrolide antibiotics, erythromycin and RXM, in patients with squamous cell carcinoma of the lung prevent tumour cell growth, invasion and metastasis. This suggestion may be supported by the findings that rapamycin, a 31-membered macrolide antibiotic with immunosuppressive activities, can inhibit metastastic tumour cell growth and can control the growth of established tumours, when the agent was injected into mice for 7 days [41].

In conclusion, the results from the present study demonstrate that the therapeutic mode of action of macrolide antibiotics on chronic inflammatory airway diseases is, in part, due to its suppressive activity on matrix metalloproteinase-2 and -9 production. Thus, macrolide antibiotics may reduce the extracellular spread of inflammation through the inhibition of matrix metalloproteinases.

\section{References}

1. Iino Y, Toriyama M, Kudo K, et al. Erythromycin inhibition of lipopolysaccharide-stimulated tumour necrosis factor alpha production by human monocytes in vitro. Ann Otol Rhinol Laryngol 1992; 101: Suppl. 157; 16-20.

2. Kudoh S, Azuma A, Yamamoto M, Izumi T, Ando M. Improvement of survival in patients with diffuse panbronchiolitis treated with low-dose erythromycin. Am J Respir Crit Care Med 1998; 157: 1829-1832.

3. Keicho N, Kudoh S. Diffuse panbronchiolitis: role of macrolides in therapy. Am J Respir Med 2002; 1: 119-131.

4. Jaffe A, Francis J, Rosenthal M, Bush A. Long-term azithromycin may improve lung function in children with cystic fibrosis. Lancet 1998; 351: 420.

5. Equi A, Balfour-Lynn IM, Bush A, Rosenthal M. Long-term azithromycin in children with cystic fibrosis: a randomized, placebo-controlled crossover trial. Lancet 2002; 360: 978984.

6. Nadel JA. Inflammation and asthma. J Allergy Clin Immunol 1984; 73: 651-653.

7. Miyachi Y, Yoshida A, Imamura S, Niwa Y. Effect of antibiotics on the generation of reactive oxygen species. J Invest Dermatol 1986; 68: 449-453.

8. Konno S, Asano K, Kurakawa M, et al. Antiasthmatic activity of a macrolide antibiotic, roxithromycin: analysis of possible mechanisms in vitro and in vivo. Int Arch Allergy Immunol 1994; 105: 308-316.

9. Shimane $\mathrm{T}$, Asano $\mathrm{K}$, Suzuki $\mathrm{M}$, et al. Influence of a macrolide antibiotic, roxithromycin, on mast cell growth and activation in vitro. Med Inflamm 2001; 10: 323-332.

10. Suzaki H, Asano K, Ohki S, et al. Suppressive activity of a macrolide antibiotic, roxithromycin, on pro-inflammatory cytokine production in vitro and in vivo. Med Inflamm 1999; 8: 199-204.

11. Asano K, Kamakazu T, Hisamitsu T, Suzaki H. Modulation of Th2 type cytokine production from human peripheral blood leukocytes by a macrolide antibiotic, roxithromycin, in vitro. Int Immunophacol 2001; 1: 1913-1921.

12. Ohno I, Ohtani H, Nitta Y, et al. Eosinophils as a source of matrix metalloproteinases-9 in asthmatic airway inflammation. Am J Respir Cell Mol Biol 1997; 16: 212-219.

13. Herouy $\mathrm{Y}$, Mellios $\mathrm{P}$, Bandemir E, et al. Inflammation in stasis dermatitis upregulates MMP-1, MMP-2 and MMP-13 expression. J Dermatol Science 2001; 25: 198-205.

14. Murphy G, Docherty AJ. The matrix metalloproteinases and their inhibitors. Am J Respir Cell Mol Biol 1992; 7: 120-125.

15. Hashimoto $\mathrm{N}$, Kawabe $\mathrm{T}$, Hara $\mathrm{T}$, et al. Effect of erythromycin on matrix metalloproteinase- 9 and cell migration. J Lab Clin Med 2001; 137: 176-183.

16. Asano K, Kamakazu K, Hisamitsu T, Suzaki H. Suppressive activity of macrolide antibiotics on nitric oxide production from nasal polyp fibroblasts in vitro. Acta Otolaryngol 2003; 123: $1064-1069$

17. Desaki M, Takizawa H, Ohtoshi $\mathrm{T}$, et al. Erythromycin suppresses nuclear factor-kB and activator protein-1 activation in human bronchial epithelial cells. Biochem Biophys Res Commun 2000; 267: 124-128.

18. Cataldo DD, Tournoy $\mathrm{KG}$, Vermaelen $\mathrm{K}$, et al. Matrix metalloproteinase- 9 deficiency impairs cellular infiltration and bronchial hyperresponsiveness during allergen-induced airway inflammation. Am J Pathol 2002; 161: 491-498.

19. Koyama M, Tateno M, Shirotuka M. Absorption, metabolism and excretion of RU 28965 in human. Chemotherapy 1988; 36: 164-183.

20. Noma T, Aoki K, Hayashi M, et al. Effect of roxithromycin on $\mathrm{T}$ lymphocyte proliferation and cytokine production elicited by mite antigen. Int Immunopharmac 2001; 1: 201-210.

21. Tomashefski JF, Abramowsky CR, Dahms BB. The pathology of cystic fibrosis. In: Davis PB, ed. Cystic Fibrosis. New York, Marcell Dekker, 1993; pp. 435-489.

22. Forsgren K, Fukami S. Endoscopic and Caldwell-Luc approaches in chronic maxillary sinusitis: a comparable histopathologic study on preoperative and postoperative mucosal morphology. Ann Otol Rhinol Laryngol 1995; 104: 350-357.

23. Al-Rawi MM, Edelstein DR, Erlandson RA. Changes in nasal epithelium in patients with severe chronic sinusitis: a clinicopathologic and electron microscopic study. Laryngoscope 1998; 108: 1816-1823.

24. Lechapt-Zalcman E, Coste A, Pia d'Ortho M, et al. Increased expression of matrix metalloproteinase-9 in nasal polyps. J Pathol 2001; 193: 233-241.

25. Birkedal-Hansen H, Moore WG, Bodden MK, et al. Matrix metalloproteinases: a review. Crit Rev Oral Biol Med 1993; 4: 197-250.

26. Fessler L, Duncan K, Fessler JH, et al. Characterization of the procollagen IV cleavage products produced by a specific tumor collagenase. J Biol Chem 1984; 259: 9783-9789.

27. Huhtala P, Tuuttila A, Chow LT, et al. Complete structure of the human gene for $92-\mathrm{kDa}$ type IV collagenase. Divergent regulation of expression for the 92- and 72killodalton enzyme genes in HT-1080 cells. J Biol Chem 1991; 266: 16485-16490.

28. Wasylyk C, Gutman A, Nicholson R, Wasylyk B. The c-Ets oncoprotein activates the stromelysin promoter through the same elements as several non-nuclear oncoprotein. EMBO $J$ 1991; 10: 1127-1134.

29. Sato H, Seiki M. Regulatory mechanism of $92 \mathrm{kDa}$ type IV collagenase gene expression which is associated with invasiveness of tumor cells. Oncogene 1993; 8: 395-405. 
30. Frisch SM, Morisaki JH. Positive and negative transcriptional elements of the human type IV collagenase gene. Mol Cell Biol 1990; 10: 6524-6532.

31. Huhtala P, Humphries MJ, McCarthy JB, et al. Cooperative signaling by $\alpha 5 \beta 1$ and $\alpha 4 \beta 1$ integrins regulates metalloproteinase gene expression in fibroblasts adhering to fibronectin. J Cell Biol 1995; 129: 867-879.

32. Xie B, Laouar A, Huberman E. Fibronectin-mediated cell adhesion is required for induction of $92-\mathrm{kDa}$ type IV collagenase/gelatinase (MMP-9) gene expression during macrophage differentiation. J Biol Chem 1998; 273: 11576-11582.

33. Wang JH, Manning BJ, Wu QD, et al. Endotoxin/ lipopolysaccharide activates $\mathrm{NF}-\kappa \mathrm{B}$ and enhances tumour cell adhesion and invasion through a $\beta 1$ integrin-dependent mechanism. J Immunol 2003; 170: 795-804.

34. Lazaar AL, Amrani Y, Hsu J, et al. CD40-mediated signal transduction in human airway smooth muscle. J Immunol 1998; 161: 3120-3127.

35. Okamoto SI, Mukaida N, Yasumoto $\mathrm{K}$, et al. The interleukin-8 AP-1 and $\mathrm{\kappa B}$-like sites are genetic end targets of FK-506-sensitive pathway accompanied by calcium mobilization. J Biol Chem 1994; 269: 8582-8589.
36. Zhao DM, Xue HH, Chida K, et al. Effect of erythromycin on ATP-induced intracellular calcium response in A549 cells. Am J Physiol Lung Cell Mol Physiol 2000; 278: L726L736.

37. Hayashi T, Ueno Y, Okamoto T. Oxidoreductive regulation of nuclear factor $\mathrm{\kappa B}$ - involvement of a cellular reducing catalyst thioredoxin. J Biol Chem 1993; 268: 11380-11388.

38. Kan H, Xie Z, Finkel MS. TNF- $\alpha$ enhances cardiac myocyte NO production through MAP kinase-mediated NF- $\mathrm{BB}$ activation. Am J Physiol 1999; 277: H1641-H1646.

39. Idesaki M, Okazaki H, Takizawa H. Effect of 14-membered ring macrolide on transcription factors in human bronchial epithelial cells. Jpn J Antibiotics 2001; 54: Suppl. C, 43-45.

40. Schutz A, Schneidenbach D, Aust G, et al. Differential expression and activity status of MMP-1, MMP-2 and MMP-9 in tumor and stromal cells of squamous cell carcinomas of the lung. Tumor Biol 2002; 23: 179-184.

41. Guba M, Breitenbuch P, Steibauer M, et al. Rapamycin inhibits primary and metastatic tumor growth by antiangiogenesis: involvement of vascular endothelial growth factor. Nature Med 2002; 8: 128-135. 